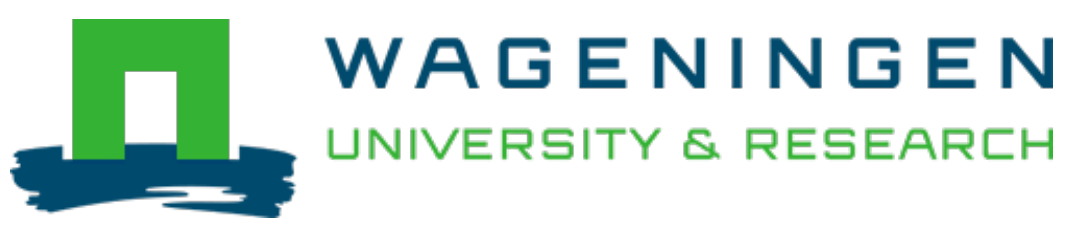

\title{
Cell type-specific transcriptomics in the plant embryo using an adapted INTACT protocol
}

\author{
Plant Embryogenesis \\ Palovaara, Joakim; Weijers, Dolf \\ https://doi.org/10.1007/978-1-0716-0342-0 11
}

This publication is made publicly available in the institutional repository of Wageningen University and Research, under the terms of article $25 \mathrm{fa}$ of the Dutch Copyright Act, also known as the Amendment Taverne. This has been done with explicit consent by the author.

Article 25 fa states that the author of a short scientific work funded either wholly or partially by Dutch public funds is entitled to make that work publicly available for no consideration following a reasonable period of time after the work was first published, provided that clear reference is made to the source of the first publication of the work.

This publication is distributed under The Association of Universities in the Netherlands (VSNU) 'Article $25 \mathrm{fa}$ implementation' project. In this project research outputs of researchers employed by Dutch Universities that comply with the legal requirements of Article $25 \mathrm{fa}$ of the Dutch Copyright Act are distributed online and free of cost or other barriers in institutional repositories. Research outputs are distributed six months after their first online publication in the original published version and with proper attribution to the source of the original publication.

You are permitted to download and use the publication for personal purposes. All rights remain with the author(s) and / or copyright owner(s) of this work. Any use of the publication or parts of it other than authorised under article $25 \mathrm{fa}$ of the Dutch Copyright act is prohibited. Wageningen University \& Research and the author(s) of this publication shall not be held responsible or liable for any damages resulting from your (re)use of this publication.

For questions regarding the public availability of this publication please contact openscience.library@wur.nl 


\title{
Chapter 11
}

\section{Cell Type-Specific Transcriptomics in the Plant Embryo Using an Adapted INTACT Protocol}

\section{Joakim Palovaara and Dolf Weijers}

\begin{abstract}
Cells differentiate from undifferentiated precursors in order to establish the tissues of vascular plants. The different cell types and stem cells are first specified in the early embryo. How cell type specification is instructed by transcriptional control on a genome-wide level is poorly understood. A major hurdle has been the technical challenge associated with obtaining cellular transcriptomes in this inaccessible tissue. Recently, we adapted a two-component genetic labeling system called INTACT to isolate nuclei and generate a microarray-based expression atlas of the cell types in the early Arabidopsis thaliana embryo. Here we present a step-by-step description of the adapted INTACT protocol, as well as the approach to generate transcriptomic profiles. This protocol has been adapted to account for using seeds with embryos of various developmental stages as a starting material, and the relatively few cell type-specific nuclei that can be isolated from embryos.
\end{abstract}

Key words Embryo, Cell type-specific, Nucleus, Isolation, Transcriptome

\section{Introduction}

The mature land plant is the product of continuous tissue and organ formation processes that are already initiated in the early embryo. During embryogenesis, the primary meristems are formed to foster the production of specialized cell types, all with unique functions, from undifferentiated stem cells [1]. The differentiation of cells requires reprogramming of the genetic regulatory network; however, how this is achieved at the genome-wide level in the early embryo has only recently been the subject of intense research. It has been a considerable challenge to determine transcriptomes from embryo-derived cells due to technical limitations. The primary challenge has been to adapt cell-specific genome-wide approaches to the relatively small plant embryo, which in seed plants is embedded within the endosperm and seed coat. Among the approaches suitable for such an adaption is INTACT (isolation of nuclei tagged in specific cell types) [2] and here we will describe an adapted step- 
by-step protocol of INTACT that can be used to isolate cell typespecific nuclei during early embryo development in the flowering plant Arabidopsis thaliana.

INTACT is a two-component genetic labeling system that was originally developed for use on Arabidopsis roots [2, 3]. By coexpressing a biotin ligase recognition peptide (BLRP), integrated in a nuclear targeting fusion (NTF) protein together with Green Fluorescent Protein (GFP) and a nuclear lamina localization domain, and an E. coli biotin ligase enzyme (BirA) in the same cell, selective biotinylation of the NTF occurs. Exploiting this, Deal and Henikoff [2] used magnetic beads coated with streptavidin, which has a high affinity for biotin, and a magnet to isolate only targeted biotintagged nuclei from a crude nuclear preparation for transcriptomic profiling. Since then, INTACT has been used for several -omics studies in plants and animals [4-12]. Recently, we adapted INTACT to determine genome-wide expression patterns in cell types of the Arabidopsis embryo [13]. This expression atlas provides a cell-specific complement to available transcriptomic data from the Arabidopsis embryo [14-16]. We chose INTACT because its two-component approach does not rely on only one cell typespecific promoter as a selection step, and as such it circumvents the need for the tissue or cell type-specific promoters driving BirA and NTF expression being exclusive to the embryo in the seed, which is often not the case $[13,14]$. Consequently, manual isolation of embryos is not necessary and thus whole seeds can be used as starting material. Also, increasing numbers of embryo-expressed promoters have become available. This made it possible to target specific cell types in the early Arabidopsis embryo by expressing a modified version of BirA (to facilitate translation) from an embryoenriched promoter $(p W O X 2, p S C R)$ and drive NTF expression with a collection of cell type-specific promoters [13] (Fig. la).

The adapted INTACT protocol described here differs from the original protocol in several steps to account for the different starting material (seeds) and developmental stages of the Arabidopsis embryo, as well as the lower numbers of biotin-tagged nuclei that can be isolated. In addition to the adapted protocol, we also describe the microarray-based approach used to generate transcriptomic profiles from biotin-tagged nuclei. This protocol can be used to target any embryo cell type in Arabidopsis, provided that plant lines with suitable cell type-specific promoters are available.

\section{Materials}

Prepare all solutions with nuclease-free water. Handle, store, and prepare commercially available products as instructed by the manufacturers. 
a

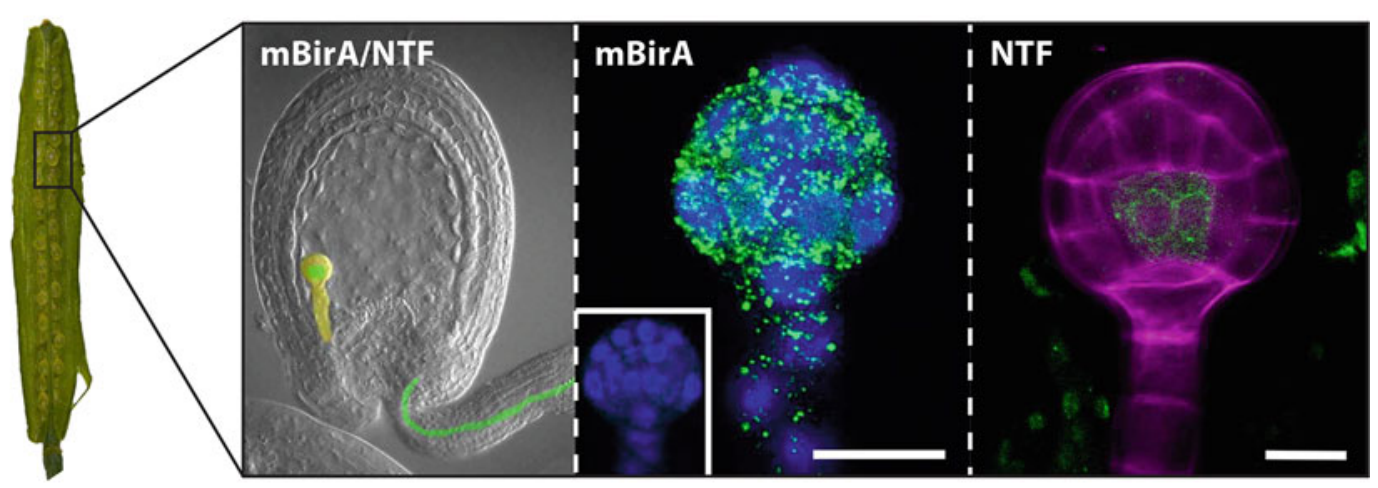

b

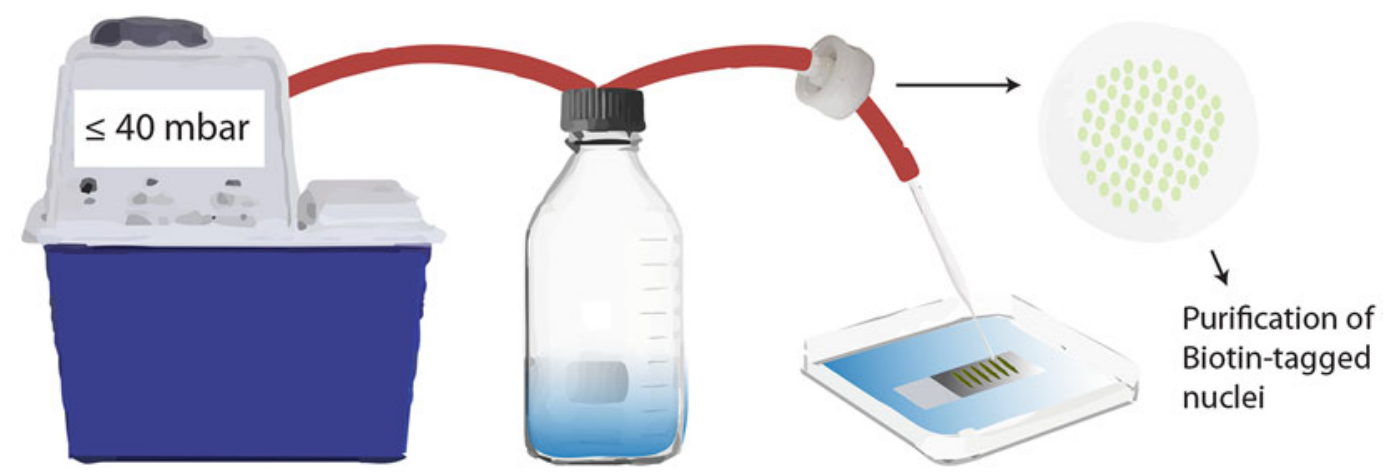

Fig. 1 Principle of INTACT and setup of seed isolation system. (a) Example of the genetic two-component approach to tag nuclei in desired cell types with biotin in the early Arabidopsis embryo. Overlapping modified BirA (mBirA; yellow) and NTF (green) specifically mark the vascular precursor cell types in the embryo. Immunostaining show whole-embryo mBirA-3xMyc expression (anti-Myc tag) when driven by the WOX2 promoter [13]. Counterstaining by DAPI (blue) and inset show negative control (Col-0). NTF is expressed from the Arabidopsis IQD15 promoter [13]. Fluorescence imaging was performed on a Leica SP5-II system (HyD detector). Scale bars represent $10 \mu \mathrm{m}$. (b) Schematic illustration of the seed isolation system. A slide with exposed seeds is placed in a $120 \times 120 \mathrm{~mm}$ square petri dish and covered with $1 \times$ PBS. The seeds are suctioned up onto a $20 \mu \mathrm{m}$ nylon net filter with a Pasteur pipette connected, with rubber tubing, to a filter holder and water vacuum pump generating $\leq 40$ mbar of vacuum. $1 \times$ PBS is continuously supplemented. Isolated seeds are homogenized, a crude nuclear extract is prepared and biotin-tagged nuclei are purified
2.1 Seed Isolation
1. Microscope slides. System
2. Double-sided adhesive tape.
3. Hypodermic needle.
4. Pasteur pipette.
5. Rubber tubing.
6. $120 \times 120 \mathrm{~mm}$ petri dish.
7. Stereomicroscope.
8. Steriflip-NY $20 \mu \mathrm{m}$ filter. 


\subsection{Purification of biotin-Tagged Nuclei}

9. $25 \mathrm{~mm}$ in-line filter holder.

10. Water vacuum pump.

1. Transgenic plants that coexpress BirA and NTF and label nuclei in an embryonic cell type of interest. A large collection of Arabidopsis plant lines targeting different cell types in the embryo is available [13].

2. $10 \times$ Phosphate-buffered saline $(10 \times \mathrm{PBS}): 1.37 \mathrm{M} \mathrm{NaCl}$, $27 \mathrm{mM} \mathrm{KCl}, 100 \mathrm{mM} \mathrm{Na} 2 \mathrm{HPO}_{4}$, and $18 \mathrm{mM} \mathrm{KH} \mathrm{PO}_{4}$. Adjust $\mathrm{pH}$ to 7.0 and autoclave or filter-sterilize. Dilute to $1 \times$ prior to use. $10 \times$ PBS can be stored at room temperature for several months.

3. $1.5 \mathrm{ml}$ Safe-Lock tubes.

4. $2 \mathrm{ml}$ Safe-Lock tubes.

5. $15 \mathrm{ml}$ conical tubes.

6. Liquid nitrogen.

7. $4.8 \mathrm{~mm}$ metal ball bearings.

8. Mixer mill MM400.

9. Nuclei purification buffer (NPB): $20 \mathrm{mM}$ MOPS $\mathrm{pH}$ 7.0, $40 \mathrm{mM} \mathrm{NaCl}, 90 \mathrm{mM} \mathrm{KCl}, 2 \mathrm{mM}$ EDTA, and $0.5 \mathrm{mM}$ EGTA. Filter-sterilize the solution. Add $0.5 \mathrm{mM}$ spermidine, $0.2 \mathrm{mM}$ spermine, and $1 \times$ cOmplete Protease inhibitor tablet shortly prior to use and keep on ice.

10. NPBc buffer: NPB containing $1 \%(\mathrm{w} / \mathrm{v})$ casein; keep at room temperature.

11. NPBt buffer: NPB containing 0.1\% (v/v) Triton X-100; keep on ice.

12. Protector RNase Inhibitor.

13. $40 \mu \mathrm{m}$ cell strainer.

14. Tabletop refrigerated centrifuge for $1.5 \mathrm{ml}$ and $15 \mathrm{ml}$ tubes.

15. M-280 streptavidin-coated Dynabeads.

16. End-over-end rotator.

17. $4^{\circ} \mathrm{C}$ cold room.

18. Flow purification column: $1 \mathrm{ml}$ Rainin LTS pipette tip, OctoMACS separator magnet and multistand, two-way stopcock, $10 \mathrm{ml}$ plastic serological pipette, Parafilm, and Pipet-Aid.

19. 4',6-diamidino-2-phenylindole (DAPI).

20. Neubauer improved hemocytometer.

2.3 RNA Isolation and Transcriptome Profiling
1. TRIzol reagent.

2. Vortex mixer. 
3. Chloroform.

4. Isopropanol.

5. Absolute ethanol.

6. Magnetic separation rack.

7. $1.5 \mathrm{ml}$ DNA LoBind Eppendorf tubes.

8. GlycoBlue (Invitrogen, catalog no. AM9515).

9. $100{ }^{\circ} \mathrm{C}$ heat block.

10. DNase I recombinant, RNase-free.

11. RNeasy Micro Kit.

12. SpeedVac Vacuum Concentrator.

13. Ovation Pico WTA System V2 and ENCORE biotin Module (NuGEN, catalog no. 3302 and 4200).

14. PCR machine.

15. NanoDrop 3300.

16. Agilent 2100 Bioanalyzer.

17. Microarray instruments.

18. GeneChip Arabidopsis Gene 1.1 ST 24-array plate and singlearray strips (Applied Biosystems, catalog no. 901913 and 901793).

\section{Methods}

\subsection{Isolation of Seeds with Embryos of a Predetermined Developmental Stage}

Carry out all procedures at room temperature unless otherwise specified.

1. Emasculate a set number of flowers by removing the anthers from Arabidopsis transgenic plants where BirA and NTF expression overlap in the embryonic cell type of interest (see Note 1).

2. After $24 \mathrm{~h}$ in a plant growth chamber $\left(22^{\circ} \mathrm{C}, 16 \mathrm{~h}\right.$ light $/ 8 \mathrm{~h}$ dark) manually pollinate the exposed stigmas (see Note 2 ).

3 . Collect the siliques after a predefined time interval when they contain seeds with embryos of the desired developmental stage (see Note 3).

4. Adhere the siliques to slides with double-sided tape $(\sim 10$ siliques/slide) and expose the seeds by opening the silique carpels along the septum with a needle.

5. Transfer a slide to a $120 \times 120 \mathrm{~mm}$ square petri dish and cover it with $1 \times$ PBS. Isolate seeds under a stereomicroscope by suctioning them up onto a $20 \mu \mathrm{m}$ nylon net filter with a Pasteur pipette connected to a $25 \mathrm{~mm}$ filter holder and a water vacuum pump (Fig. 1b) (see Note 4). 


\subsection{Purification of biotin-Tagged Nuclei}

6. Once all slides have been processed ( see Note 5), remove the filter and release the seeds by dipping it several times in two or three ice-cold $2 \mathrm{ml}$ tubes containing $1 \times$ PBS.

1. Remove the $1 \times$ PBS from the $2 \mathrm{ml}$ tubes using a pipette and then add a $4.8 \mathrm{~mm}$ ball bearing to each tube before freezing them in liquid nitrogen.

2. Transfer the tubes to a mixer mill with adaptor racks precooled in liquid nitrogen. Homogenize the seeds with a vibrational frequency of 30 Hertz for $2 \times 30 \mathrm{~s}$.

3. Resuspend with $1 \mathrm{ml}$ ice-cold NPB using a cut pipette tip and transfer the suspensions to an ice-cold $15 \mathrm{ml}$ tube. Fill up with NBP to $10 \mathrm{ml}$ and add 200 units of RNase inhibitor before rotating the tube to mix.

4. Filter the suspension through a $40 \mu \mathrm{m}$ cell strainer into a new ice-cold $15 \mathrm{ml}$ tube and centrifuge at $1200 \times g$ at $4{ }^{\circ} \mathrm{C}$ for $7 \mathrm{~min}$.

5. Remove the supernatant and resuspend the crude nuclear preparation with $1 \mathrm{ml} \mathrm{NPB}$ using a cut pipette tip and, after transfer to an ice-cold $1.5 \mathrm{ml}$ tube, add $10 \mu \mathrm{l}$ of washed M-280 streptavidin-coated Dynabeads (see Note 6).

6. Incubate the mixture for $30 \mathrm{~min}$ at $4{ }^{\circ} \mathrm{C}$ with end-over-end rotation to facilitate the binding of beads to the biotin-tagged nuclei. Prepare the flow purification column (steps 7-9).

7. Treat $1 \mathrm{ml}$ Rainin LTS pipette tips with NPBc to prevent nonbead-bound nuclei to adhere to the tip wall and place them horizontally.

8. After $20 \mathrm{~min}$, insert a tip into the groove of an OctoMACS separator magnet without introducing cracks in the tip wall (see Note 7). Arrange the tip-magnet assembly vertically in a $4{ }^{\circ} \mathrm{C}$ cold room.

9. Attach a two-way stopcock to the narrow end of the tip to control liquid flow rate and then rinse and preload it with ice-cold NPBt.

10. After incubation (step 6), dilute the bead and nuclei mixture with ice-cold $9 \mathrm{ml} \mathrm{NPBt}$ in a $15 \mathrm{ml}$ tube and mix by rotating the tube 5-10 times.

11. Slowly draw the mixture into a $10 \mathrm{ml}$ plastic serological pipette with Parafilm wrapped around its tip using an electronic serological pipetting device.

12. Fasten the $10 \mathrm{ml}$ pipette to the broad opening of the $1 \mathrm{ml}$ Rainin LTS pipette tip by twisting it half a turn and remove the pipetting device. 
13. Open the stopcock slowly and let the mixture pass the magnet at a rate at or below $0.75 \mathrm{ml} / \mathrm{min}$, which permits the efficient capture of bead-bound nuclei to the tip wall (see Note 8 ).

14. Detach the serological pipette when empty and remove any bubbles from the $1 \mathrm{ml}$ tip with a Pasteur pipette as they can cause captured bead-bound nuclei to release from the magnet.

15. Remove the pipette tip once all mixture has passed the magnet and wipe the outside tip wall with a moist tissue. Wash of any non-bead-bound nuclei from the inner tip wall by slowly drawing NPBt in and out five times without disturbing the bead-bound nuclei attached to the wall (see Note 9).

16. Rinse the tip with $1 \mathrm{ml} \mathrm{NPBt}$ into an ice-cold $1.5 \mathrm{ml}$ tube and repeat steps 10-15 to maximize purity (see Note 10).

17. Rinse the tip a second time and centrifuge at $1000 \times g$ at $4{ }^{\circ} \mathrm{C}$ for $5 \mathrm{~min}$ to pellet the purified bead-bound (biotin-tagged) nuclei.

18. Remove the supernatant and resuspend the pellet in $25 \mu \mathrm{l}$ ice-cold NPB. Proceed directly with RNA isolation or store at $-80{ }^{\circ} \mathrm{C}$ for later use (see Note 11 ).

19. To determine purity and recovery efficiency, add $1 \mu \mathrm{l}$ of DAPI $(2 \mu \mathrm{g} / \mathrm{ml})$ to $4 \mu \mathrm{l}$ of sample from step $\mathbf{1 8}$, incubate in darkness for $5 \mathrm{~min}$, and estimate the ratio of stained bead-bound nuclei to unbound nuclei (purity) and to expected number of biotintagged nuclei in the starting material (recovery efficiency) using a hemocytometer (see Note 12).

\subsection{RNA Isolation and Transcriptome Profiling}

1. Add $500 \mu \mathrm{l}$ of TRIzol reagent to the purified nuclei in step $\mathbf{1 8}$ and vortex for $5 \mathrm{~min}$ for nuclei lysis. Use a magnetic separation rack to pellet beads and transfer the lysate to a new $1.5 \mathrm{ml}$ tube.

2. Add $100 \mu \mathrm{l}$ of chloroform, vortex for $15 \mathrm{~s}$ and incubate for $3 \mathrm{~min}$.

3. Centrifuge at $12000 \times g$ at $4{ }^{\circ} \mathrm{C}$ for $15 \mathrm{~min}$ and transfer the upper aqueous phase $(\sim 330 \mu \mathrm{l})$ carefully to an ice-cold $1.5 \mathrm{ml}$ DNA LoBind tube.

4. Add $250 \mu \mathrm{l}$ isopropanol and $2 \mu \mathrm{l}$ of the coprecipitant GlycoBlue $\left(15 \mathrm{mg} / \mathrm{ml}\right.$ ) and briefly vortex. Incubate overnight at $-20^{\circ} \mathrm{C}$.

5. Centrifuge at full speed at $4{ }^{\circ} \mathrm{C}$ for $30 \mathrm{~min}$ to pellet precipitated RNA and remove the supernatant.

6. Wash the pellet by adding $500 \mu \mathrm{l}$ of $75 \%$ ethanol, vortex and centrifuge at full speed at $4{ }^{\circ} \mathrm{C}$ for $15 \mathrm{~min}$. Remove the supernatant and air-dry for $10 \mathrm{~min}$ on ice.

7. Add $10 \mu \mathrm{l}$ water and incubate at $60{ }^{\circ} \mathrm{C}$ for $10 \mathrm{~min}$ to resuspend the RNA. 
8. Digest genomic DNA with $\sim 14$ units of DNase I for 5 min and clean up the RNA using the Qiagen RNeasy Micro kit.

9. Vacuum-concentrate the RNA to $5 \mu$ and store at $-80^{\circ} \mathrm{C}$ until further use (see Note 13).

10. For microarray-based transcriptome profiling, amplify and label the RNA using the NuGEN Ovation Pico WTA System V2 and ENCORE biotin Module, respectively (see Note 14).

11. Measure amplified cDNA yield using a NanoDrop and hybridize equal amounts to an Arabidopsis Gene 1.1 ST 24-array plate or single-array strips according to the manufacturer's instructions ( see Note 15).

12. Analyze transcriptomic profiles using the MADMAX pipeline [17] or similar platforms.

\section{Notes}

1. Select preanthesis flower buds that show white petals for emasculation and remove all opened flowers to avoid selfpollination. Mark the emasculated flowers by tying a colored string around the inflorescence stem. The number of flowers to emasculate for each transgenic line depends on the expected yield of biotin-tagged nuclei, which can be estimated by determining the recovery efficiency (see step 19 in Subheading 3.2).

2. Manual pollination should not take longer than 1 h to minimize variations in embryo development at the time of seed isolation. To achieve this, multiple people may have to perform this step.

3. Determine the time-interval after manual pollination of each transgenic line at which seeds contain the most embryos of a desired developmental stage. Silique collection should be performed at the same time point of day for each experiment to minimize circadian rhythm effects.

4. Minimize seed damage by using a vacuum pressure at or below 40 mbar and seed dehydration by continuously replenishing the petri dish with fresh $1 \times$ PBS.

5. Time spent for seed isolation can be shortened by involving multiple people: 1-2 people collect and place siliques on slides, 1 person opens the siliques, and 1 person suctions up the seeds. With this setup, it is possible to process $\sim 10$ siliques per minute.

6. $10 \mu \mathrm{l} \mathrm{M-280} \mathrm{streptavidin-coated} \mathrm{Dynabeads}\left(\sim 6 \times 10^{6}\right.$ beads) is more than sufficient to isolate the low numbers of biotintagged nuclei expected from Arabidopsis embryos. 
7. Cracks in the tip wall can trap non-bead-bound nuclei and other cell debris during bead-bound (biotin-tagged) nuclei purification.

8. Rates above $0.75 \mathrm{ml} / \mathrm{min}$ can result in reduced yield.

9. This step significantly improves purity due to the low number of biotin-tagged nuclei isolated from Arabidopsis embryos.

10. An alternative purification system is available where beadbound nuclei are captured directly to the wall of a $15 \mathrm{ml}$ tube placed in a magnet [18]. While this setup simplifies the procedure, it has not been extensively tested with regards to yield or purity when very low numbers of biotin-tagged nuclei are expected.

11. The purified biotin-tagged nuclei can be used in several -omics applications (see e.g., $[4,5,7,9,10,12]$ ) provided the number of isolated nuclei is sufficient and/or the starting material has been cross-linked.

12. In addition to INTACT execution, purity can vary depending on the transgenic line used and cell type of interest [13].

13. RNA concentration can be quantified by qRT-PCR using a total RNA standard curve.

14. Pool RNA from biological replicates to increase RNA amounts if necessary and amplify all RNA samples simultaneously to reduce technical variances and to avoid batch-to-batch effects. Ovation Pico WTA System V2 uses an oligo(dT)-random primer mixture that amplifies both pre- and postprocessed mRNA transcripts, which is the preferred amplification strategy for nuclear RNA. Besides microarray, the RNA can be optimized for RNA-Seq by removing the highly abundant rRNA [10].

15. cDNA quality can be assessed by measuring size distribution using an Agilent 2100 Bioanalyzer.

\section{Acknowledgments}

The authors thank Tatyana Radoeva and Thomas Nakel for providing the Arabidopsis seed image in Fig. la and for image editing in Fig. Ib, respectively. This work was supported by the Federation of European Biochemical Societies (FEBS) to J.P. and by the European Research Council (ERC; Starting Grant "CELLPATTERN"; Contract number 281573) and ERA-CAPS (EUROPEC; 849.13.006) to D.W. 


\section{References}

1. Palovaara J, de Zeeuw T, Weijers D (2016) Tissue and organ initiation in the plant embryo: a first time for everything. Annu Rev Cell Dev Biol 32:47-75

2. Deal RB, Henikoff S (2010) A simple method for gene expression and chromatin profiling of individual cell types within a tissue. Dev Cell 18:1030-1040

3. Deal RB, Henikoff S (2011) The INTACT method for cell type-specific gene expression and chromatin profiling in Arabidopsis thaliana. Nat Protoc 6:56-68

4. Amin NM, Greco TM, Kuchenbrod LM, Rigney MM, Chung M-I, Wallingford JB et al (2014) Proteomic profiling of cardiac tissue by isolation of nuclei tagged in specific cell types (INTACT). Development 141:962-973

5. Foley SW, Gosai SJ, Wang D, Selamoglu N, Solitti AC, Köster T et al (2017) A global view of RNA-protein interactions reveals novel root hair cell fate regulators. Dev Cell 41:204-220. e5

6. Henry GL, Davis FP, Picard S, Eddy SR (2012) Cell type-specific genomics of Drosophila neurons. Nucleic Acids Res 40:9691-9704

7. Mo A, Mukamel EA, Davis FP, Luo C, Henry GL, Picard $S$ et al (2015) Epigenomic signatures of neuronal diversity in the mammalian brain. Neuron 86:1369-1384

8. Moreno-Romero J, Santos-González J, Hennig L, Köhler C (2017) Applying the INTACT method to purify endosperm nuclei and to generate parental-specific epigenome profiles. Nat Protoc 12:238-254

9. Park K, Kim MY, Vickers M, Park J-S, Hyun Y, Okamoto T et al (2016) DNA demethylation is initiated in the central cells of Arabidopsis and rice. Proc Natl Acad Sci U S A 1 13:15138-15143

10. Reynoso MA, Pauluzzi GC, Kajala K, Cabanlit S, Velasco J, Bazin J et al (2018) Nuclear transcriptomes at high resolution using retooled INTACT. Plant Physiol 176:270-281

11. Ron M, Kajala K, Pauluzzi G, Wang D, Reynoso MA, Zumstein K et al (2014) Hairy root transformation using agrobacterium rhizogenes as a tool for exploring cell type-specific gene expression and function using tomato as a model. Plant Physiol 166:455-469

12. Steiner FA, Talbert PB, Kasinathan S, Deal RB, Henikoff S (2012) Cell-type-specific nuclei purification from whole animals for genomewide expression and chromatin profiling. Genome Res 22:766-777

13. Palovaara J, Saiga $S$, Wendrich JR, van 't Wout Hofland N, van Schayck JP, Hater F et al (2017) Transcriptome dynamics revealed by a gene expression atlas of the early Arabidopsis embryo. Nat Plants 3:894-904

14. Belmonte MF, Kirkbride RC, Stone SL, Pelletier JM, Bui AQ, Yeung EC et al (2013) Comprehensive developmental profiles of gene activity in regions and subregions of the Arabidopsis seed. Proc Natl Acad Sci U S A 110: E435-E444

15. Casson S, Spencer M, Walker K, Lindsey K (2005) Laser capture microdissection for the analysis of gene expression during embryogenesis of Arabidopsis. Plant J 42:111-123

16. Slane D, Kong J, Berendzen KW, Kilian J, Henschen A, Kolb M et al (2014) Cell typespecific transcriptome analysis in the early Arabidopsis thaliana embryo. Development 141:4831-4840

17. Lin K, Kools H, de Groot PJ, Gavai AK, Basnet $\mathrm{RK}$, Cheng $\mathrm{F}$ et al (2011) MADMAX-management and analysis database for multiple omics experiments. J Integr Bioinform 8:160

18. Wang D, Deal RB (2015) Epigenome profiling of special plant cell types using a streamlined INTACT protocol and ChIP-seq. Methods Mol Biol 1284:3-25 